Jurnal Penelitian Hasil Hutan

Forest Products Research Journal

Vol. 13 No. 5 (1995) pp. 176 - 185

\title{
FURFURILASI PADA KAYU TUSAM (Pinus merkusii Jungh. et de Vr.) DAN MANGIUM (Acacia mangium Willd.) Furfurylation on tusam and mangium
}

\author{
Oleh/By \\ Jamal Balfas
}

\section{$S u m m a r y$}

Wood specimens of tusam (Pinus merkusii Jungh. et de Vr.) and mangium (Acacia mangium Willd.) were air-dried to approximately 16-18\% moisture content. One group of the specimens was further oven-dried to reach moisture content of 6-8\%. Furfurylation was undertaken by soaking wood specimens for 24 hours in a $98 \%$ furfuryl alcohol solution containing $0.35 \%(v / v)$ of $\mathrm{ZnCl}_{2}$ as catalyst. Furfurylated specimens were then cured at $100^{\circ} \mathrm{C}$ for 48 hours. Wood characteristics observed in this study include dimentional stability, hardness, compression strength and shear strength.

Test results showed that the initial wood specimens of tusam had a higher radial but a lower tangential swelling rates than those specimens of mangium. Furfurylation could improve wood dimentional stability of both species by more than $90 \%$ on tusam and $75 \%$ on mangium. Values of hardness, compression strength and shear strength of tusam were markedly lower than mangium. After furfurylation, however, tusam had a greater hardness than mangium. Furfurylation could increase hardness, compression strength and shear strength of tusam by more than $94 \%, 83 \%$ and $76 \%$ respectively. A lower wood mechanical improvements were encountered with the mangium specimens.

\section{PENDAHULUAN}

Kegiatan penelitian dalam bidang pemuliaan pohon pada dasarnya telah dilakukan oleh hampir setiap negara di dunia. Hasil penelitian ini secara periodik didiskusikan dalam forum simposium dan konferensi yang diselenggarakan dalam tingkat nasional maupun internasional. Forum ilmiah tersebut tidak hanya membahas aspek silvikultur dan manajemen pada tegakan hutan tanaman, tapi juga mencakup karakteristik kayu yang dihasilkan dari sistem tersebut. Sifat kayu yang diteliti secara intensif umumnya berkaitan dengan karakteristik fisis dan mekanis kayu, seperti berat jenis, panjang serat, tebal dinding sel, kekuatan serat, dan beberapa karakteristik lainnya yang dianggap penting bagi industri kertas. 
Dewasa ini industri kayu di Indonesia mulai dihadapkan dengan hasil hutan tanaman yang telah dikembangkan pada areal hutan rakyat dan areal HTI di wilayah konsesi HPH. Sebagian dari areal hutan tanaman tersebut dibangun dengan komposisi pohon super, yang diperoleh melalui pemuliaan genetis atau kultur jaringan, disertai dengan optimalisasi lingkungan pertumbuhan seperti pengaturan jarak tanam, irigasi, pemupukan, pemangkasan, penjarangan dan praktek silvikultur modern lainnya. Kayu yang diperoleh dari sistem ini ternyata memiliki karakteristik yang berbeda dengan kayu sejenis yang diperoleh dari hutan alam, sehingga menimbulkan permasalahan baru dalam proses pengolahannya. Hal ini mungkin berhubungan dengan hasil pengamatan Bendtsen (1978) yang menyimpulkan bahwa kayu yang diperoleh dari hutan buatan ("manmade forest") memiliki nilai berat jenis dan karakteristik serat yang lebih rendah daripada kayu sejenis dengan ukuran diameter yang sama berasal dari hutan alam.

Desakan kebutuhan kayu yang terus meningkat dan tekanan ekonomi yang berlangsung makin serius dalam dasawarsa terakhir cenderung melandasi kebijaksanaan penanaman jenis pohon cepat tumbuh yang memiliki daur panen relatif singkat. Sementara itu hasil studi di negara maju menunjukkan bahwa kelompok jenis pohon cepat tumbuh umumnya mengandung lebih banyak porsi kayu muda (juvenile wood) dibandingkan dengan kelompok jenis berdaur panen panjang. Sifat inferior kayu muda dibandingkan dengan kayu dewasa (mature wood) telah dilaporkan oleh Dadswell (1958), Erickson dan Arima (1974) dan beberapa penulis lainnya. Penurunan karakteristik fisis dan mekanis pada kayu yang diperoleh dari hutan buatan tampaknya tidak berakibat serius bagi industri kertas, tetapi bagi industri kayu utuh (solidwood) dan keperluan konstruksi hal tersebut dapat menimbulkan banyak permasalahan baru dalam proses pengolahan dan penggunaan produknya. Di samping masalah penurunan sifat fisis dan mekanis, kayu hutan tanaman umumnya memiliki sifat keawetan dan stabilitas dimensi yang lebih rendah dibandingkan dengan kayu sejenis dari hutan alam. Karakteristik ini merupakan masalah serius dalam penggunaan kayu untuk keperluan bangunan.

Sejalan dengan perkembangan masalah di atas, sejak tahun 1960-an para ahli teknologi kayu melakukan penelitian secara intensif dalam upaya penyempurnaan karakteristik kayu melalui berbagai modifikasi kimia. Cara yang paling umum dilakukan adalah memasukkan (impregnasi) senyawa kimia yang dapat bereaksi dengan komponen dasar pada dinding sel kayu (selulosa, hemiselulosa dan lignin) sehingga diperoleh penyempurnaan pada struktur kimia kayu, yang diikuti dengan perbaikan karakteristik fisis dan mekanis kayu. Salah satu cara praktis yang termasuk ke dalam sistem tersebut adalah perlakuan furfurilasi, yaitu impregnasi kayu dengan bahan furfuryl alcohol, yang mampu menyelenggarakan reaksi silang dengan gugus hidroksil di dalam dinding sel.

Dari beberapa studi yang telah dilakukan sebelumnya diketahui bahwa furfurilasi dapat meningkatkan berbagai sifat keteguhan kayu, serta meningkatkan ketahanan kayu terhadap serangan jamur dan serangga (Goldstein dan Dreher, 1961). Furfurilasi dapat dilakukan dengan cara difusi pada kayu kering udara (kadar air 10 sampai dengan $18 \%$ ), sehingga membuatnya lebih praktis dari pada cara impregnasi dengan menggunakan senyawa lainnya. Dalam studi ini akan dilakukan pengujian pendahuluan apakah furfurilasi mampu memperbaiki sifat-sifat inferior pada kayu hutan 
tanaman. Tujuan penelitian ini adalah menyempurnakan karakteristik kayu yang berasal dari hutan tanaman, sehingga dapat memenuhi persyaratan teknis yang dibutuhkan dalam penggunaan kayu untuk keperluan bangunan.

\section{BAHAN DAN METODE PENELITLAN}

\section{A. Persiapan contoh uji}

Bahan kayu yang digunakan dalam penelitian ini terdiri dari 2 jenis kayu yang berasal dari hutan tanaman, yaitu tusam (Pinus merkusii Jungh.) dan mangium (Acacia mangium Willd.). Kayu bulat (log) dari masing-masing jenis digergaji menjadi sortimen berukuran tebal 1,3 dan $5 \mathrm{Cm}$, lebar 5 dan $10 \mathrm{Cm}$ dan panjang $50 \mathrm{Cm}$.

Semua sortimen dikeringkan secara alami (diangin-angin) dalam ruang laboratorium pengerjaan kayu hingga mencapai kadar air kering udara (15 - 18\%). Sortimen kemudian diserut dan diseleksi untuk memperoleh contoh uji bebas cacat.

Untuk masing-masing jenis kayu dibuat 30 contoh uji stabilitas dimensi berukuran $10 \mathrm{~mm} \times 10 \mathrm{~mm} \times 100 \mathrm{~mm}$ dengan arah orientasi serat radial dan tangensial. Untuk pengujian sifat keteguhan tekan tegak lurus serat, keteguhan geser sejajar serat dan kekerasan dibuat contoh uji berukuran $25 \mathrm{~mm} \times 25 \mathrm{~mm} \times 50 \mathrm{~mm}$ sebanyak 60 buah dan ukuran $25 \mathrm{~mm} \times 25 \mathrm{~mm} \times 75 \mathrm{~mm}$ sebanyak 15 buah dari masing-masing jenis kayu.

\section{B. Perlakuan furfurilasi}

Larutan furfuril alkohol yang digunakan dalam penelitian ini berasal dari Aldrich, Amerika dengan kemurnian $98 \%$. Sebagai katalis digunakan larutan $5 \% \mathrm{ZnCl}_{2}$ dengan pelarut air. Komposisi campuran kedua larutan tersebut yang digunakan dalam penelitian ini adalah 95 : 5 menurut volume larutan. Perlakuan furfurilasi dilakukan dengan cara merendam contoh uji selama 24 jam dalam larutan furfuril alkohol. Setelah perendaman, contoh uji dibungkus dengan kertas aluminium foil, kemudian dimasukkan dalam oven pada suhu $100^{\circ} \mathrm{C}$ selama 48 jam.

\section{Pengukuran dan pengujian}

Efektifitas perlakuan furfurilasi ditentukan berdasarkan perubahan berat pada contoh uji, yaitu dengan cara penimbangan contoh uji sebelum dan sesudah perlakuan. Pada contoh uji stabilitas dimensi dilakukan juga pengukuran dimensi radial dan tangensial pada contoh uji saat sebelum dan sesudah furfurilasi. Pengujian stabilitas dimensi kayu dilakukan dengan menggunakan alat swellometer. Efektivitas furfurilasi dalam peningkatan stabilitas dimensi kayu ditentukan berdasarkan nilai efisiensi anti pengembangan (EAP), yang dihitung dengan rumus berikut :

$$
\mathrm{EAP}=\frac{\% \text { Pengembangan pada Kontrol }-\% \text { Pengembangan pada Perlakuan }}{\% \text { Pengembangan pada Kontrol }}
$$

Pengujian sifat keteguhan kayu yang meliputı keteguhan tekan tegak lurus serat, keteguhan geser sejajar serat dan kekerasan ditentukan menurut prosedur yang diuraikan oleh Nurwati (1988). 


\section{Rancangan percobaan}

Penelitian ini melibatkan 3 faktor utama, yaitu jenis kayu, orientasi serat dan metode furfurilasi. Faktor pertama terdiri dari 2 jenis kayu, faktor ke dua terdiri dari 2 arah serat (radial dan tangensial), sedangkan faktor ke tiga terdiri dari 3 taraf perlakuan, yaitu kontrol, perendaman contoh uji pada kadar air kering udara dan perendaman contoh uji pada kadar air sekitar 7\%. Untuk mengurangi variasi contoh uji menurut perlakuan digunakan metode pengambilan contoh uji secara berpasangan (paired samples). Data yang diperoleh dalam penelitian ini diolah menurut prosedur analisa statistik 3 arah yang diuraikan oleh Mustafa (1994).

\section{HASIL DAN PEMBAHASAN}

Kadar air kering udara pada contoh uji yang digunakan dalam penelitian ini adalah $15,10 \%$ pada kayu tusam dan $18,57 \%$ pada kayu mangium. Sedangkan pada kelompok contoh uji yang dike- ringkan dalam oven pada suhu $60{ }^{\circ} \mathrm{C}$ selama 3 hari sebelum perlakuan furfurilasi, kayu tusam memiliki kadar air keseimbangan sekitar $6 \%$ dan mangium sekitar $8 \%$. Perbedaan kandungan air pada kedua jenis kayu ini mungkin berhubungan dengan perbedaan karakteristik fisis dan kimia antara dua jenis kayu tersebut. Kayu mangium yang memiliki berat jenis dan kandungan ekstraktif yang lebih besar cenderung memiliki tempat ikatan air yang lebih banyak, sehingga memiliki nilai kadar air keseimbangan yang lebih tinggi dari pada kayu tusam.

Perubahan dimensi (pengembangan) kayu selama 3 hari perendaman dalam air menunjukkan bahwa kayu tusam memiliki derajat pengembangan radial yang lebih besar daripada kayu mangium (Tabel 1). Sebaliknya pengembangan kayu mangium pada arah tangensial adalah lebih besar dari pada kayu tusam. Dalam periode awal (4 jam) rendaman, perubahan dimensi pada kayu tusam berlangsung lebih cepat dibandingkan dengan kayu mangium baik pada arah radial maupun tangensial (Gambar 1A). Perbedaan ini menunjukkan bahwa kayu tusam lebih mudah mengalami pembasahan atau lebih permeabel daripada kayu mangium.

Tabel 1. Karakteristik stabilitas dimensi kayu

Table 1. Characteristics of wood dimentional stability

\begin{tabular}{|c|c|c|c|c|c|c|}
\hline $\begin{array}{c}\text { Jenis kayu } \\
\text { (Wood species) }\end{array}$ & $\begin{array}{c}\text { Perlakuan } \\
\text { (Treatment) }\end{array}$ & $\begin{array}{c}\text { Arah serat } \\
\text { (Grain direction) }\end{array}$ & $\begin{array}{l}\text { Penambahan berat } \\
\text { (Weight gain), }(\%)\end{array}$ & $\begin{array}{l}\text { Penambahan dimensi } \\
\text { (Dimentional gain), }(\%)\end{array}$ & $\begin{array}{l}\text { Pengembangan } \\
(\text { Swelling). }(\%)\end{array}$ & $\begin{array}{l}\text { EAP } \\
(\%)\end{array}$ \\
\hline \multirow[t]{6}{*}{ Tusam } & Control & Radial & . & $\dot{-}$ & $\begin{array}{l}2,23 \\
3,43\end{array}$ & - \\
\hline & & Tangential & $\therefore$ & 58 & 3,43 & - \\
\hline & Metode 1 & Radial & 52,39 & 2,86 & 0,22 & 90,13 \\
\hline & (Method I) & Tangential & 33.98 & 2,89 & 0,30 & 91,25 \\
\hline & Metode 2 & Radial & 56,54 & 2,90 & 0,17 & 92,38 \\
\hline & (Method 2) & Tangential & 34,90 & 3,31 & 0,27 & 92,13 \\
\hline \multirow[t]{6}{*}{ Mangium } & Control & Radial & - & . & 2,00 & - \\
\hline & & Tangential & 8 & - & 3,82 & \\
\hline & Metode 1 & Radial & 16,73 & 1,40 & 0,49 & 75,50 \\
\hline & (Method I) & Tangential & 17,18 & 3,45 & 0,89 & 76,70 \\
\hline & Metode 2 & Radial & 22,15 & 1,84 & 0,41 & 79.50 \\
\hline & (Method 2) & Tangential & 24,23 & 4,29 & 0,70 & 81,68 \\
\hline
\end{tabular}

Keterangan (Remarks): EAP = Efisiensi anti pengembangan (Anti-swelling efficiency), Metode 1 dan metode 2 masing-masing adalah perlakuan furfurilasi yang dilakukan pada contoh uji dengan kadar air kayu kering udara dan kadar air sekitar $6.8 \%$ (Method 1 and method 2 are the furfurylation applied to wood specimens at airdry and $6-8 \%$ moisture content respectively)

For. Prod. Res. J. Vol. 13 No. 5 (1995) 

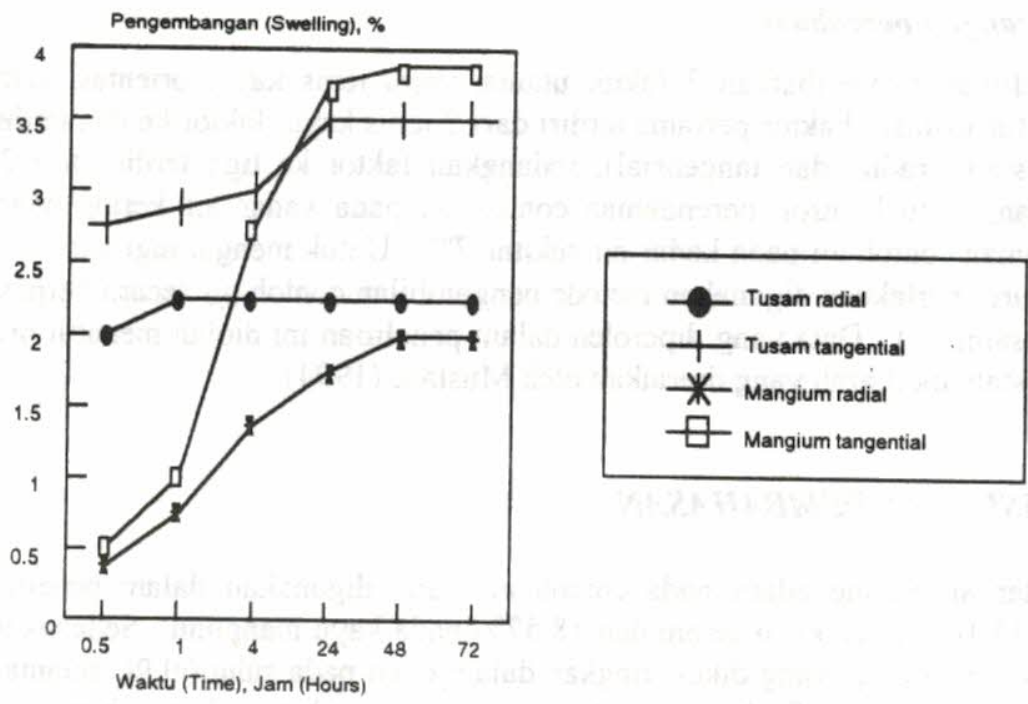

Gambar 1A. Pengembangan kayu kontrol selama 72 jam rendaman dalam air Figure 1A. Swelling of the control specimens during 72-hour immersion in water

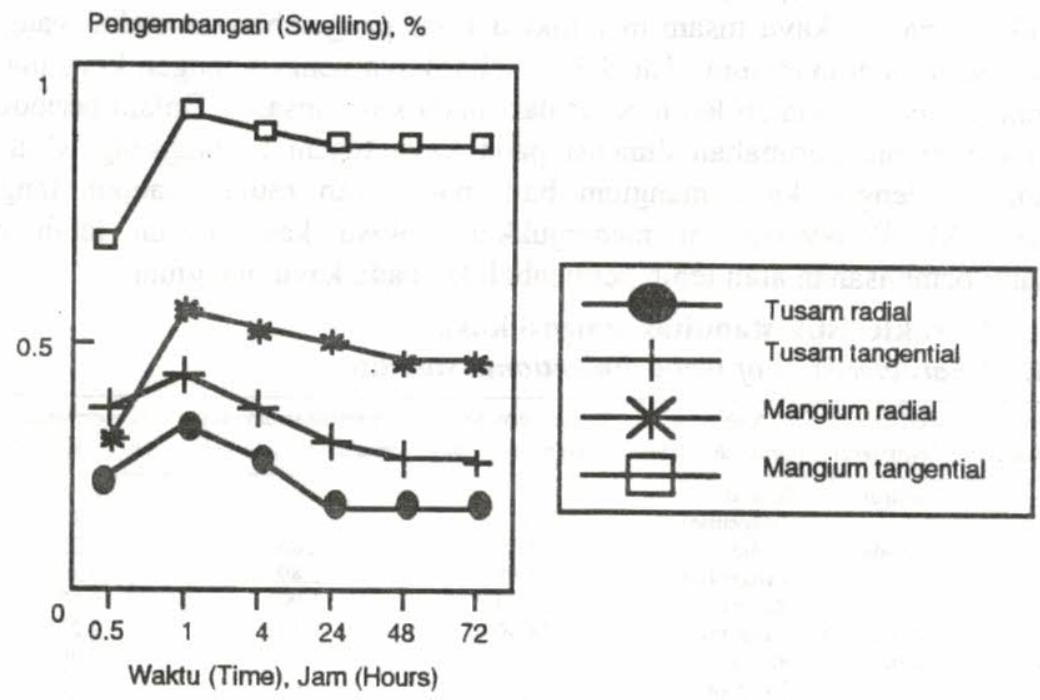

Gambar 1B. Pengembangan kayu yang difurfurilasi dengan metode I selama 72 jam rendaman dalam air

Figure 1B. Swelling of the method I furfurilated specimens during 72-hour immersion in water 


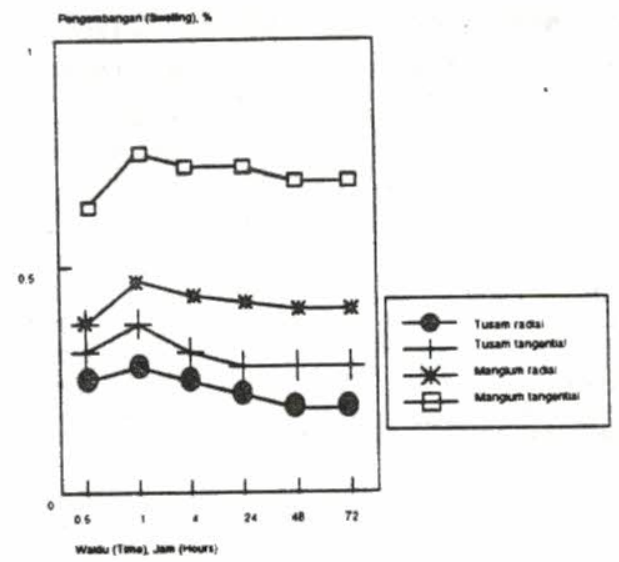

Gambar 1C. Pengembangan kayu yang difurfurilasi dengan metode II selama 72 jam rendaman dalam air

Figure 1C. Swelling of the method II furfurilated specimens during 72-hour immersion in water

Perlakuan furfurilasi pada contoh uji stabilitas kayu menyebabkan penambahan berat dan dimensi pada contoh uji (Tabel 1). Penambahan tersebut secara nyata $(\mathrm{p}<$ 0.05 ) dipengaruhi oleh faktor jenis kayu dan interaksi antara faktor jenis kayu dan metode perlakuan. Penambahan berat pada kayu tusam lebih besar daripada kayu mangium. Hal ini berarti bahwa reaksi senyawa furfuryl alcohol dengan komponen serat kayu terjadi secara lebih masif pada kayu tusam dibandingkan dengan kayu mangium. Perbedaan tersebut juga menunjukkan bahwa kayu tusam bersifat lebih mudah dimasuki larutan (permeabel) dibandingkan kayu mangium. Penambahan berat pada kayu tusam tidak berbeda nyata $(p>0,05)$ menurut metode perlakuan, sedangkan pada kayu mangium penambahan berat akibat furfurilasi dipengaruhi oleh metode perlakuannya. Contoh uji kayu mangium yang direndam dalam larutan furfuril alkohol pada keadaan kadar air kering udara (18\%) mengalami penambahan berat yang lebih rendah dibandingkan dengan contoh uji yang memiliki kadar air sekitar $8 \%$. Perbedaan ini tampaknya berhubungan dengan sifat permeabilitas antara kedua jenis kayu sebagaimana telah dibahas sebelumnya. Hasil di atas menunjukkan bahwa permeabilitas kayu mangium mengalami peningkatan dengan berkurangnya kandungan air pada kayu tersebut.

Pengaruh perlakuan furfurilasi terhadap stabilitas dimensi kayu bervariasi menurut faktor jenis kayu, orientasi serat, metode perlakuan, interaksi antara faktor jenis kayu dan orientasi serat, serta interaksi antara orientasi serat dan metode perlakuan (Tabel 2). Pengaruh perlakuan furfurilasi pada sifat pengembangan kayu tusam adalah lebih besar dibandingkan dengan kayu mangium. Hal ini juga ditunjukkan oleh nilai efisiensi anti pengembangan (Tabel 1) pada kayu tusam lebih dari $90 \%$, sedangkan pada kayu mangium kurang dari $82 \%$. Perbedaan ini terutama berhubungan dengan tingkat furfurilasi yang lebih tinggi pada kayu tusam sebagaimana ditunjukkan oleh prosentase pertambahan berat yang lebih tinggi daripada kayu mangium (Tabel 1). 
Tabel 2. Sidik ragam pengembangan kayu selama 72 jam rendaman dalam air Table 2. Anova of wood swelling during 72-hour immersion in water

\begin{tabular}{lcrc}
\hline $\begin{array}{c}\text { Sumber keragaman } \\
\text { (Source of variation) }\end{array}$ & $\begin{array}{c}\text { Derajat bebas } \\
\text { (Degrees of freedom) }\end{array}$ & $\begin{array}{c}\text { Kuadrat tengah } \\
\text { (Mean square) }\end{array}$ & $\begin{array}{c}\text { F-hitung } \\
\text { (F-calculated) }\end{array}$ \\
\hline Jenis kayu (Wood species), A & 1 & 1,170 & $6,52^{* *}$ \\
Arah serat (Grain direction), B & 1 & 6,208 & $34,59^{* *}$ \\
Periakuan (Treatment), C & 2 & 42,133 & $234,73^{* *}$ \\
Interaksi (Interaction) A x B & 1 & 0,845 & $4,71^{*}$ \\
Interaksi (Interaction) A x C & 2 & 0,177 & 0,38 \\
Interaksi (Interaction) B x C & 2 & 2,723 & $0,0001^{* *}$ \\
Interaksi (Interaction) A x B x C & 2 & 0,191 & 0,3532 \\
\hline
\end{tabular}

Keterangan (Remarks): ${ }^{*}$ Nyata (Significant); ${ }^{* *}$ Sangat nyata (Very significant)

Nilai pengembangan kayu pada arah radial lebih kecil daripada arah tangensial. Perbedaan nilai pengembangan radial dan tangensial berlaku umum baik pada kontrol maupun pada kayu yang difurfurilasi. Hal ini berarti bahwa perlakuan furfurilasi merubah sifat pengembangan secara proporsional pada arah radial dan tangensial. Dengan perkataan lain, perlakuan furfurilasi tidak menghilangkan perbedaan alami antara pengembangan radial dan tangensial. Kayu yang difurfurilasi pada kondisi kadar air kering udara (Gambar 1B) memiliki sifat pengembangan yang lebih besar dibandingkan dengan kayu yang difurfurilasi pada kadar air sekitar $6-8 \%$ (Gambar 1C). Perbedaan ini tampaknya berhubungan dengan tingkat furfurilasi yang lebih tinggi pada kelompok kayu terakhir.

Karakteristik mekanis kayu tusam dan mangium disajikan pada Tabel 3. Pengaruh furfurilasi terhadap penyempurnaan sifat mekanis kayu secara umum beragam menurut faktor jenis kayu, perlakuan dan interaksi antara kedua faktor tersebut (Tabel 4). Nilai kekerasan, keteguhan tekan tegak lurus serat dan keteguhan geser sejajar serat pada kontrol kayu tusam lebih rendah dibandingkan dengan kontrol kayu mangium. Namun demikian setelah furfurilasi, nilai kekerasan dan keteguhan geser pada kayu tusam menjadi lebih tinggi daripada kayu mangium. Kayu tusam yang difurfurilasi umumnya mengalami penambahan nilai keteguhan lebih dari $100 \%$, sedangkan penambahan keteguhan pada kayu mangium umumnya kurang dari $60 \%$. Hal ini terutama disebabkan oleh tingkat furfurilasi yang lebih besar pada kayu tusam sebagaimana ditunjukkan oleh nilai pertambahan berat kayu akibat furfurilasi (Tabel 3).

Penyempurnaan sifat keteguhan pada kedua jenis kayu tersebut pada dasarnya disebabkan oleh adanya intrusi gugus furfuril ke dalam struktur dinding sel kayu dan membentuk jembatan polimer di antara rantai lignoselulosa melalui reaksi ikatan silang (crosslinking), sehingga terjadi suatu modifikasi semacam penebalan pada dinding sel kayu dan mengisi sebagian rongga pada jaringan kayu. Modifikasi ini secara makroskopis meningkatkan keteguhan masif jaringan kayu. 
Tabel 3. Karakteristik mekanis kayu

Table 3. Wood mechanical characteristics

\begin{tabular}{cccccc}
\hline $\begin{array}{c}\text { Jenis Kayu dan perlakuan } \\
\text { (Wood species and treatment) })\end{array}$ & $\begin{array}{c}\text { Contoh } \mathrm{Uji}_{j \mathrm{i}} \\
\text { (Test specimen) })\end{array}$ & $\begin{array}{c}\text { Arah serat } \\
\text { (Grain direction) })\end{array}$ & $\begin{array}{c}\text { Penambahan berat } \\
\text { (Weight gain), \% }\end{array}$ & $\begin{array}{c}\text { Keteguhan } \\
\text { (Strength) }\end{array}$ & $\begin{array}{c}\text { Penambahan keteguhan } \\
\text { (Strength gain),\% }\end{array}$ \\
\hline
\end{tabular}

\section{Plnus}

Control

Kekerasan
(Hardness)
Tekan tegak lurus
serat (Compression
perpendicular to grain)

Radial

Tangential

300

(2)

Geser sejajar serat
(Shear parrallel 10 grain)

Radial

Tangential

Radial

Tangential

Metode 1

(Method I)

$\begin{gathered}\text { Kekerasan } \\ \text { (Hardiness) }\end{gathered}$
Tekan tegak lunus serat(Com-
pression perpendicular to grain)

Radial

Tangential

Radial

Tangential

Geser sejajar serat
(Sheor parrallel to grain)

Radial

Tangential

Metode 2

(Method 2)

$\begin{gathered}\text { Kekerasan } \\ \text { (Hardness) }\end{gathered}$
Tekan tegak lurus serat(Com-
pression perpendicular to grain)

Radial

Tangential

Radial

Tangential

Geser sejajar serat

Radial

(Shear parrallel to grain)

Tangential

44,91

125,33

29,25

39,77

156,85

104,26

182,82

33,38

78,18

28,66

126,01

41,73

94,00

41,73

107,53

30,61

35,55

82,88

31,87

130,68

29,39

76,32

118,52

\section{Manglum}

Control

Kekerasan
(Hardness)
Tekan tegak lurus serat(Com-
pression perpendicular to grain)
Geser sejajar serat
(Shear parrallel to grain)

Radial

Tangential

Radial

Tangential

Radial

Tangential

160,8

271,4

Metode 1
Method I

Metode 2

(Method 2)
Radial

Tangential

Radial

Tangential

Radial

Tangential

Radial

Tangential

Radial

Tekan tegak lurus serat( $C$ ompression perpendicular to grain)

Geser sejajar serat

(Shear parrallel to grain)
365

$\begin{array}{ll}. & 365 \\ . & 377\end{array}$

235,1

230,6

113,1

174,3

$7,15 \quad 497,0$

$7,15 \quad 551,0$

$11,57 \quad 377,6$

$11,29 \quad 350,8$

$15,60 \quad 149,0$

$12,98 \quad 225,9$

S01,0

$\begin{array}{ll}13,41 & 501,0 \\ 13,41 & 598,0\end{array}$

$\begin{array}{ll}11,73 & 437,2 \\ 11,13 & 381,7\end{array}$

16,26

13,69 
Tabel 4. Sidik ragam sifat mekanis kayu

Table 4. Anova of wood mechanical characteristics

\begin{tabular}{|c|c|c|c|c|c|c|c|}
\hline \multirow{3}{*}{$\begin{array}{l}\text { Sumber keragaman } \\
\text { (Source of variation) }\end{array}$} & \multirow{3}{*}{$\begin{array}{c}\text { Derajat bebas } \\
\text { (Degrees of freedom) }\end{array}$} & \multicolumn{6}{|c|}{ Sifat mekanis (Mechanical properties) } \\
\hline & & \multicolumn{2}{|r|}{ KKR } & \multicolumn{2}{|c|}{ TTLS } & \multicolumn{2}{|l|}{ GSS } \\
\hline & & KT & F-hit. & KT & F-hit. & KT & F-hit. \\
\hline $\begin{array}{l}\text { Jenis kayu, A } \\
\text { (Wood species, } A \text { ) }\end{array}$ & 1 & 41081.67 & $8.64^{* *}$ & 253760.07 & $170.19^{* *}$ & 244.02 & 0.58 \\
\hline $\begin{array}{l}\text { Arah serat, B } \\
(\text { Grain direction, B) }\end{array}$ & 1 & 24806.67 & $5.22^{*}$ & 1306.67 & 0.88 & 101764.02 & $243.04^{* *}$ \\
\hline $\begin{array}{l}\text { Perlakuuan, C } \\
\text { (Treatment, C) }\end{array}$ & 2 & 471061.67 & $99.10^{* *}$ & 141727.40 & $95.05^{* *}$ & 44195.22 & $105.55^{* *}$ \\
\hline $\begin{array}{l}\text { Interaksi } \mathrm{A} \times \mathrm{B} \\
\text { (Interaction } A \times B)\end{array}$ & 1 & 2406.67 & 0.51 & 5645.40 & 3.79 & 340.82 & 0.81 \\
\hline $\begin{array}{l}\text { Interaksi } \mathrm{A} \times \mathrm{C} \\
(\text { Interaction } A \times C \text { ) }\end{array}$ & 2 & 8998167 & $18.93^{* *}$ & 10018.87 & $6.72^{* * *}$ & 6465.22 & $15.44^{* *}$ \\
\hline $\begin{array}{l}\text { Interaksi B } \times C \\
\text { (Interaction } B \times C \text { ) }\end{array}$ & 2 & 6521.67 & 1.37 & 864.27 & 0.58 & 4728.32 & $11.29^{* *}$ \\
\hline $\begin{array}{l}\text { Interaksi } \mathrm{A} \times \mathrm{B} \times \mathrm{C} \\
\text { (Interaction } A \times B \times C \text { ) }\end{array}$ & 2 & 2761.67 & 0.58 & 2952.80 & 1.98 & 1522.32 & $3.64^{*}$ \\
\hline
\end{tabular}

Keterangan (Remarks):

KKR $=$ Kekerasan (Hardness), TTLS = Keteguhan tekan tegak lurus serat (Compression perpendicular to grain), GSS $=$ Keteguhan geser sejajar serat (Shear parrallel to grain), KT = Kuadrat tengah (Mean square), F-hit = F-hitung $(F$-calculated)

* Nyata (Significant), ${ }^{* *}$ Sangat nyata (Very significant)

\section{KESIMPULAN DAN SARAN}

\section{A. Kesimpulan}

Perlakuan furfurilasi dapat meningkatkan sifat stabilitas dimensi, keteguhan mekanis dan keawetan pada kayu tusam dan mangium. Efektivitas furfurilasi ditentukan oleh permeabilitas kayu dan kadar air kayu. Penyempurnaan stabilitas dimensi dan keteguhan kayu bersifat proporsional dengan tingkat furfurilasi.

\section{B. Saran}

Penelitian furfurilasi perlu dilakukan pada contoh kayu berukuran besar, seperti reng, usuk, papan dan balok. Untuk menghindari ketergantungan terhadap barang impor dan penyempurnaan nilai ekonomis dari perlakuan ini kiranya perlu dilakukan sintesa furfuryl alcohol dari limbah pertanian.

\section{DAFTAR PUSTAKA}

Bendtsen, B.A. 1978. Proporties of wood from improved and intensively managed trees. Forest Prod. J. 28(10): 61-72.

Dadswell, H.E. 1958. Wood structure variations occuring during free growth and their influence on properties. J.Inst.Wood Sci.(1): 11-32. 
Erickson, H.D. T. Arima. 1974. Douglas-fir wood quuality studies. Part II: Effects of age and stimulated growth on fibrill angle and chemical constifuents. Wood Sci. and Tech. (8):255-256.

Goldstein, T.S. and W.A.Dreher. 1961. Stuble furfuryl alcohol impreguating solution. Ind.Eng.Chem. 52(11):57-58.

Mustafa, Z. 1994. Panduan microstat untuk mengolah data statistik. Edisi III. Andi Offset, Yogyakarta.

Nurwati Hajib. 1988. Pengaruh jenis monomer dan dosis radiasi terhadap sifat fisis dan mekanis kayu plastik. Thesis Pasca Sarjana Program S-2, Fakultas Kehutanan IPB. Bogor. Tidak diterbitkan.

Stamm, A.J. 1977. Dimensional stabilization of wood with furfuryl alcohol resin. In: I.S. Goldstein (Ed.): wood technology; chemical aspects. Washington D.C. American Chem. Soc. 